\title{
Writing well: health and the power to make images
}

Mark Robinson University of Durham, Durham

\begin{abstract}
There is increasing interest in connections between writing and wellbeing, but a perceived tension between writing well and writing to improve health. This paper gives a brief outline of some dominant literary thinking in this area, explores views of this orthodoxy among two groups of writers, examines the writing process and evidence of how it affects wellbeing, and goes on to relate how such evidence relates to recent psychological/clinical findings. Eighty-four per cent of those interviewed testified to therapeutic effects, but tensions existed around quality and catharsis. Bucci's multiple code account of the referential cycle is related to the creative writing process, and the paper concludes there are indications that the process of writing well is linked to the benefits for wellbeing. It therefore suggests that the importance of literary quality, and the re-writing process involved, as well as the value of disclosure, needs to be examined further as writing is increasingly used therapeutically.

(F Med Ethics: Medical Humanities 2000;26:79-84)
\end{abstract}

Keywords: Writing; health; literary theory; psychology; poetry therapy; bibliotherapy

\section{Introduction}

There is increasing interest in connections between writing and wellbeing, but a perceived tension between writing well and writing to maintain or improve health. Whilst many people have testified that creative writing can have therapeutic effects, (for example, Leedy, ${ }^{1}$ Barr, ${ }^{2}$ Longo, ${ }^{3}$ and Bolton ${ }^{4}$ ) this is often seen as somehow ruling out the possibility of the writing's being of a high literary quality according to the dominant paradigms of "excellence" within English-speaking literary culture. This can have several effects. Writing which describes or originates in illhealth, be that mental or physical, can be dismissed as "merely therapy" and therefore of little literary value, unless written by someone who is already recognised as a writer. This can lead to reinforcement of negative images for those writing, who may feel their work is "not real writing", which can then have further damaging effects on self esteem and health. The beneficial effects of writing not directly related to trauma or experience can be overlooked, therefore reinforcing the perceived barrier between quality and therapy.

I want to put forward the hypothesis that the writing process itself is an integral part of any benefit, in addition to what we may term the purgative or cathartic effects of non-process-orientated writing, which emphasises disclosure of experience or emotion. I shall explore views of the tension between catharsis and craft, and note the differences of opinion on this among different kinds of writers. I will draw on published writings about research carried out with poets, students and users of mental health services, and finally on recent psychological research which gives some clear indications that at least some elements of "quality" are intrinsic to the therapeutic benefits of writing. Whilst not intending a wholly empirical, hard evidence-based approach, I hope to open areas for future inquiry into the relationship between the writing process and wellbeing.

\section{'Returning health: this is shown by the power to make images'}

In a diary entry from Summer 1926, Virginia Woolf describes "a whole nervous breakdown in miniature". ${ }^{6}$ She delineates the different stages: inertia, disjuncture, despair, and then gradual reawakening. Depression is associated with having "no power of phrase making", and with passive, unimaginative reading, "like a cow chewing cud". The return to a healthier state begins with a "desire to read poetry", which she says "brings back a sense of my own individuality". Alongside this comes a gradual regaining of her ability to write: "Returning health: this is shown by the power to make images; the suggestive power of every sight and word is enormously increased".

Woolf here makes a link between the mechanics of writing and mental wellbeing which is worth exploring. It is often said that it doesn't matter if a piece of writing is good if it helps you feel better or get something off your chest, but if you want to publish, it will need to communicate your experience to an audience, and it can only do this by going beyond the experience. In their introduction to Beyond Bedlam Ken Smith and Matthew Sweeney say they chose to publish "pieces that rose beyond their immediate occasion - that transmuted the original experience into art". ${ }^{7}$ Whilst it could be argued that this vision of the process misses out a crucial, difficult, yet rewarding stage for all writers - putting that "original experience" into words at all -it is revealing of the dominant literary approach to therapeutic writing. Literary excellence demands a secondary transmutation, following that of experience into words, from experiencein-language to experience-transmuted-into-art. Whilst agreeing that there is a distancing or transmuting process which must be undergone for 
writing to live for readers, I would argue that it is the control which the writer exhibits over the material which is most important, his/her conception of the relationship of language to experience, rather than what can be a rather mechanical process of transmutation and universalisation. (Kenneth Koch argues that poetry is written in what is virtually a different language from "everyday" language, one with its own rules and conventions. ${ }^{8}$ )

\section{Perspectives from literary culture}

Smith and Sweeney's approach, which is rejected by organisations such as Survivors Poetry, who consider it elitist, can be traced back to some key poetic positions of the 20th century. A broad understanding of these dominant mythologies of writing and mental health within English-speaking literary culture wil inform the later discussion. I could start by taking two contrasting quotations from modernist writers. Wallace Stevens said that: "Poetry is a process of the personality of the poet". ${ }^{9}$ Note that his definition is process-based, rather than personality-centred. He does not say poetry is a reflection of the personality of the poet, or an expression of it, but rather that poetry stems from the interaction of the personality of the poet with the medium of poetry. W H Auden summed up this up as: "The poet marries the language, and out of this marriage the poem is born". ${ }^{10} \mathrm{~T} S \mathrm{~S}$ Eliot, however, famously wrote that "Poetry is not a turning loose of emotion, but an escape from emotion; it is not the expression of personality, but an escape from personality". Studies of Eliot (for example, Ackroyd ${ }^{12}$ ) have shown how personal experience such as the mental illness of his first wife appears in his work, and have put more emphasis on the sometimes neglected sentence which follows: "But, of course, only those who have personality and emotions know what it means to want to escape from these things". Each of these views, in different ways, puts an emphasis on the writer's relationship to language and the process of the medium, rather than on the ostensible "content" of any piece of writing. This differs from simplistic versions of therapeutic writing, where the initial "writing out" is given primacy over re-writing, editing and structuring.

The school of writing most associated with mental health issues is the "confessional" school of the 1960s. This included Robert Lowell, John Berryman and Ann Sexton, all of whom suffered from mental illness. Ann Sexton actually began writing at the suggestion of her therapist when she was in a mental hospital, and her work contains many poems about both her own mental condition and her experiences in mental hospital, although she was often sceptical about how much writing actually helped her poem Ringing The Bells. The critical acceptance of the confessional school can be traced back to the influence of Freudian views of creativity. The implications of Freud's views for artists and writers are best summarised by Lionel Trilling in his essay, Art and Neurosis. ${ }^{10}$ Freud originally saw the artist "as a neurotic who escapes from reality by means of 'substitute gratifications"”.
He slightly modified this negative-seeming view later, concluding that writers had actually discovered the unconscious before he had. (Poststructuralist critics would perhaps argue that writers had the language in which the idea of the unconscious could take shape, as writing does not reflect experience but creates a reflecting space which allows us to conceptualise our experience. This parallels Winnicot's transitional space or object. Writing can be seen as existing in what Winnicott called the transitional space, being neither of the psychic inner reality nor of the objective outer reality but in a third space which allows the individual to negotiate between the other two ${ }^{14}$.

Freudian views joined strains of Romanticism to make the artist into a kind of neurotic-on-ourbehalf. Rimbaud, for instance, stood for induced neurosis: "the poet must make himself a seer by a long, prodigious, and rational disordering of all the senses. Every form of love, of suffering, of madness; he searches himself, he consumes all the poisons in him, and keeps only their quintessences". ${ }^{15}$ Edmund Wilson, in The Wound and The Bow, compares the artist to Philoctetes, a great warrior forced to live in isolation because of the stench of a suppurating wound, but whom people had to seek out despite this because they had need of his magically unerring bow. Trilling sums it up thus: "The artist is indeed unique ... in his relation to his neurosis. He is what he is by virtue of his successful objectification of his neurosis, by his shaping it and making it available to others in a way which has its effect upon their own egos in struggle."16

This vision of the neurotic-seer does not, however, necessarily support the view that writing can have benefits for wellbeing. Indeed it could be seen as quite the opposite. Alongside it goes a strong line of thought which sees poetry as essentially impersonal, as indicated by Eliot.

Jon Winokur's book of quotations, Writers on Writing, has four pages of bons mots about "angst". "Suffering is the main condition of the artistic experience" (Samuel Beckett) would be a typical quotation. ${ }^{17}$ This mythology can take on quite brutal aspects, as in some of the comments following the suicide of playwright Sarah Kane. Her agent "and close friend" Mel Kenyon said: "I don't think she was depressed ... I think she felt something more like existential despair which is what makes many artists tick." Several of the reports of her death quoted a character in her play Crave: "I write the truth and it kills me". ${ }^{18}$

A Alvarez, in Against the Gentility Principle, his landmark introduction to The New Poetry, makes an interesting distinction between the early work of Robert Lowell and Life Studies, his first "confessional" collection: "Where once Lowell tried to externalise his disturbances theologically in $\mathrm{Ca}$ tholicism and rhetorically in certain mannerisms of language and rhythm, he is now, I think, trying to cope with them nakedly, and without evasion". ${ }^{1}$

This reverses the kind of artistic process which Smith and Sweeney were apparently looking for, 
and posits the transmutation of experience through language as a form of evasion, or inhibition.

A strain of thinking which sees writing as facilitating an unconscious working out of issues has grown out of the rejection of "gentility" in favour of naked expression. This can be seen in many creative writing guidebooks and underlies much workshop practise. This works on the basis that free writing throws up material which the intellect cannot access, which can then be used as material for the shaping element of the writing process. Whilst this can clearly have personal benefits in terms of getting to grips with experience and emotion, many practitioners are still reluctant to see this as writing-as-therapy. Natalie Goldberg, whose books have been highly influential amongst creative writing tutors, reacts badly when people compare her writing workshops to therapy: "It's not therapy: it's the root of literature, direct connection with your mind." ${ }^{20}$ This actually reverses the accusation and sees the process more like therapy-as-writing. Yet this still seems stubborn given her "learning to trust your own mind". There is clearly an aversion within literary culture to the process being led by therapy rather than by art, even though the roots of that art are intrinsically linked to wellbeing. Much of this may stem from negative connotations of the word "therapy", as well as from ingrained notions of "craft" which lead to a depersonalisation of writing. (Although this would seem to be contradicted by cognitive psychology, let alone psychoanalytic thought.) This workshop practice of uncovering what Goldberg calls the "direct connection to your mind", be it ostensibly for therapeutic or literary reasons, can be related to theories about disclosure and health which I will touch upon later.

\section{Research and methodology}

To explore views about these issues, whilst looking for qualitative indications of the effects of writing, I interviewed two groups of people, all of whom wrote regularly and regarded themselves as "writers", albeit not necessarily as professionals. It should be noted that this was intended primarily to explore individuals' views of the subject, as well as some self-reported indications of therapeutic or other effects. It was not intended to provide clinical evidence, though it does indicate a need for further work similar to that of Pennebaker outlined below but focused on creative writing as such.

Group One (16 people) were involved in writing groups: they were either users of mental health support services in a National Health Service (NHS) day unit, or were in a group supported by Mind. The Mind group was largely self-sustaining, whilst the health trust group was led by an occupational therapist. Neither group was set up solely or specifically for therapeutic purposes, and all participants were outpatients or voluntary attenders of the Mind group. The Mind cabaret group wrote songs, poems and parodies about mental health. The health trust group had grown out of a residency by a poet.

Group Two (18 people) were writers contacted via internet mailing lists, whose primary practice was poetry. These included poets of all kinds and at all levels, from beginners to writers with a number of published books. They were not asked about their mental health history. All participants completed the same questionnaire, and were asked supplementary questions in interviews (group 1) or via email (group 2).

The questionnaire was in two parts. Part one was a series of questions about writing experience and their views and personal experiences of ways in which writing either affected or reflected wellbeing, and whether the perceived quality of the writing was important. Part two asked whether they agreed or disagreed (on a scale of $1-5,1$ being "Disagree strongly" and 5 "Agree strongly") with 22 statements relating to writing, the possible therapeutic uses or functions of writing, the relationship between quality and therapy, and the literary views of the relationship between creativity and suffering or mental anguish outlined above. Even with this small sample a large number of issues were raised, and there is further analysis to be done on them. What I want to do here, however, is look at the responses as a whole, and draw out some themes to do with, first, whether writing can have a therapeutic benefit for writers; second, how the writing process plays a part in any benefits, and third, views on the literary mythologies outlined earlier.The overwhelming majority of people $(84 \%$ of the total sample) said that writing had had a therapeutic use for them. Many people had used writing to explore particular incidents such as the death of parents or children, or had written journals during stressful periods in their life. Much of the language used to talk about the uses of writing saw it as a process of disclosure. Comments such as "It helped to put my feelings into words", and "It helps me to deal with things as I can look and understand what I have read" were common. This was conceived in two ways: either as "dealing" with emotions and experiences or through catharsis or "purging". "Dealing" with experience placed emphasis on the process as integral and active, seeing it as the process of formulating words and texts which assists in control of the feelings. "Purging" sees the writing process much more as packaging or containing experience, in order to get rid of it or to manage it. Some people pointed out that catharsis can be just the first stage in producing a good piece of writing fit for others to share. Interestingly, although more than $80 \%$ of people in both groups agreed with the statements "My writing helps me sort out my thoughts" and "Writing helps me get things out of my system", views on the statement "When I write something I feel I've dealt with what I write about" were much more mixed, with only a minority overall agreeing. Group 2 were significantly more likely to disagree$25 \%$ agreeing, compared with $63 \%$ of group 1 . This may suggest that for those more concerned with the rewriting process, the issues raised were more difficult to "finish off" merely by writing about themthat the process was a kind of ongoing "dealing with" more than a writing out of (or off) of experience. There was a strong feeling in both groups that 
writing did not function as a displacement activity, and should therefore be seen as a way of coming to terms with experience, of finding a language to create narratives and images, even if these did not deal directly with personal experience.

Some respondents made a useful distinction between a therapeutic use - a conscious aim - and a therapeutic function which happens almost in spite of a writer's conscious literary aims. One person, from group 2, having outlined that he believed in writing as art and craft rather than therapy, went on to say: "I am sure that some of my writing has had such a [therapeutic] use, but because of my stance vis-à-vis writing, I would not be thinking about my own writing in these terms". Another commented: "I find that writing has therapeutic effects without one trying for it". Few respondents defined very clearly what they meant by therapeutic uses. Some talked of being able to get some distance from their own experience and emotions by putting them into words, and thereby gaining a greater insight: "It can help one to be more objective sometimes-to see one's own position from an outside perspective."

Not all people saw their writing as directly related to experience, however, with a significant number of people, particularly among group 2 , disagreeing with the statement: "I write mostly about myself and my feelings and experiences", with which none of group 1 disagreed. This was despite strong agreement from all groups that they used writing as a means of self expression and that writing helped deal with personal issues. Recent sufferers from mental illness (group 1) were less concerned to assimilate and transmute experience into detached "impersonal" literary products than the more experienced poets in group 2 who put greater emphasis on language as a medium in its own right, rather than as a "container" of autobiographical content A number of people reported negative mental and physical effects if they could not write as regularly as they wanted. One person put it simply: "If I cannot write, I feel bad. When I can write, I feel good". One person described having cut down on the amount of writing she did, as a result of changes in family circumstances. This was followed by signs of mental illhealth, which disappeared when she began to write regularly again. This would seem to tie in with recent studies outlined below which have shown that writing regularly about stressful or important or emotive subjects can boost immune function activity. ${ }^{21}$

I was particularly interested to know people's views on the literary mythologies surrounding writing, therapy and quality. A recent study by Jensen and Blair of a writing group who had all been users of mental health services, identified "a tension between the cathartic expression of thoughts and feelings and the production of quality writings", a tension which had a negative, inhibiting effect on the group and individuals within it. ${ }^{5}$ This was clearly shared by the different sub-groups within my sample, although how differed significantly. Mental health service users were, on the whole, not too concerned with whether people thought their work "good" in literary terms. Their response to the statement: "Writing is not about therapy" was almost unanimous disagreement, almost the opposite to that of the poets. They did, however, almost without exception, say they redrafted their writing, and showed signs of careful reworking in the light of reader/audience response.

Although some of the poets said writing could be a painful process when not going well, and could cause stress and low self esteem, in general there was a strong feeling against the writer-as-neurotic mythology outlined earlier, and against seeing cathartic work as equal to other writing. There were many comments which echoed Smith and Sweeney's requirement of "transmutation of experience": "I think that if a piece is nothing more than personal catharsis it should stay in the drawer". Almost all group 1 disagreed with the statement that "You need to have some bad experiences or angst to write about to be a writer"' Group 2 were, however, much more likely to agree with this statement. At times members of group 1 seemed to deny their own evidence of the writing process in a wish to distance "real" writing from therapeutic writing: "While some of it is drawn from writing of a therapeutic nature, finished pieces aren't therapeutic". This would seem to beg the question when and how writing might stop being therapeutic (either in fact or in the writer's perception) as it gets near to being finished, which would require further investigation of the writing process. It also indicates how writing for therapeutic benefits and quality writing are seen within literary culture as two separate things. To sum up, there were strong indications that writers of all kinds felt they gained psychological benefits from their writing practice. Only in a few cases was this separate from the normal literary writing and redrafting process necessary for good writing of any genre, form or school. An interest in quality, in producing a text which was more than instant or an outpouring but was in some sense crafted, was clearly integral to the process of writing enhancing wellbeing, indicated, for instance, by high levels of agreement with the statement: "Rewriting and drafting helps me work out what I really meant to say" and disagreement with: "I never rewrite my poems or stories". (I acknowledge that this in many senses side-steps the issues around literary quality - who or what structures decide what is "good"-but I am more concerned here with individuals' efforts to improve their writing than with issues of reception and classification.) There was a feeling in many responses from both groups that the best writing was strengthened by a connection to traumatic emotional experiences. As one person put it: "It is true that the majority of 'therapeutic writing' is, to put it bluntly, crap, but then a lot of non-therapeutic writing is crap too and possibly the most worthwhile poetry stems from therapeutic beginnings".

\section{Recent medical research}

This research shows that the majority of people who write regularly feel that it helps them cope with and work on traumatic experiences and is beneficial 
to their mental wellbeing. This is still self reporting, however, and I want to conclude by relating some recent psychological research to the statements made. Gillie Bolton has examined some of the research carried out by one of the pioneers in this field, James W Pennebaker. ${ }^{22}$ Pennebaker found in one study that talking about trauma reduced the teller's anxiety level, which he links to the putting into words of otherwise unexpressed emotion. The problem with traumatic experiences is not so much the experience itself as "the unassimilated emotions that drive these memories to the surface of consciousness". ${ }^{22}$ Disclosure, the basis of most forms of counselling-based therapy, is primarily gained through language, and is now established as being beneficial in dealing with psychological distress. It is precisely in the assimilation of experience that writing can assist, it is a secondary language function, requiring some conscious shaping and decision making. To use Natalie Goldberg's phrase it can restore the "direct connection to your mind". Pennebaker concludes that "narrative expression, whether written or spoken, has a naturally organising (controlling and structuring) effect". ${ }^{23}$

Another recent study by Smyth et al broadens the study to physical health. ${ }^{21}$ Participants suffering from rheumatoid arthritis and asthma were asked to write about stressful life experiences for $20 \mathrm{~min}$ utes on three consecutive days. A control group wrote simply about their plans for the day. During the four-month period between writing and examination, almost half ( $47 \%)$ of participants who had written about stressful subjects showed clinical improvements in symptoms, compared with $24 \%$ within the control group. It should be noted that the writing was not done specifically or overtly for therapeutic purposes, and that the participants were asked to write "without regard for spelling or stylistic concerns". It is possible that, if they had been asked to write poems or stories about stressful subjects, the results would have been different, as the writing process-shaping, choice, revision, externalising - may have interfered with the disclosure element of the activity. To suggest that writing itself does not at times cause stress would be dishonest. As Rebecca West put it, and as supported by many of the writers in my own sample, it can be a "nauseous process". ${ }^{24}$

\section{The referential cycle and writing well}

Whilst this suggests a positive health benefit from writing about stressful subjects, it does not give us any firm indications of how the writing process may fit into the equation. Wilma Bucci's study The Power of the Narrative: A Multiple Code Account ${ }^{25}$ may, however, allow me to draw some tentative conclusions about the relation between good writing and how it is achieved, and health benefits.

Bucci's study proposes a model "to account for the effect of language, and in particular storytelling, on physical and emotional health". My description of her theoretic model is necessarily simplified. The "multiple code theory" suggests that information and experience are stored in the mind in both symbolic and sub-symbolic forms - ie in both amorphous, understood form and in symbols or images which refer to the amorphous material. Verbal representations are possible only at the symbolic level, when we have developed an image for experience or emotion. This image allows us to put a verbal label onto something we have previously only felt subconsciously or perhaps physically. These symbols - which can be visual or non-verbal as well as verbal-can then be combined in an infinite set of meaningful combinations, according to certain rules. Language is a symbolic format within this model. Through language we are able to connect to sub-symbolic or subconscious information and emotion. Language connects us to the subsymbolic system via referential links "which", Bucci says, "enable us to name what we experience, and to identify what we have named". ${ }^{26}$ Although put in a different register this is familiar to both writers and readers as one possible hallmark of writing of the very highest standard-"what oft was thought but ne'er so well expressed" as Keats put it. Language enables us to share experience, including emotional activity by, in Bucci's words, "activating internal representations of imagery and emotion". The effect of this might for instance lie behind Keats's claim that a poem should "appear almost a Remembrance", an example of "the spirit ditties of no tone".

Our connection to the sub-symbolic level is achieved via language through what Bucci terms referential activity, ie the connections made between the symbolic and sub-symbolic levels outlined above. But some kinds of language are more effective at stimulating referential activity than others. Specific, concrete words-such as apple, orange, banana-stimulate more referential activity than higher order words such as fruit, food, which in turn are more effective than abstract words such as health, motherhood, exploitation. Whilst higher order language does stimulate some referential activity, the general direction of this description would extend William Carlos Williams's oft-cited dictum "No ideas but in things" to "No ideas or emotions but in things". This is entirely in keeping with what teachers of writers find themselves stressing to students - as Natalie Goldberg's 3rd rule of writing puts it: "Be Specific". ${ }^{27}$ (Clearly abstraction has its literary uses, but I would argue that in general, creative writing should contain much more specific language than abstract, even where the end effect is perhaps "abstract".) The more specific language is the more effective it is, according to Bucci, in connecting the writer or reader to their sub-symbolic emotion and experience, and the more it can be used by them to activate images which then form the basis of emotional schemas. The referential cycle which Bucci outlines has clear parallels with the writing process as many experience it. It has four stages:

1. sub-symbolic activation-equivalent to images or rhythms brewing, before a text is started; 
2. referential phase 1: images formed, the "breakthrough" in thinking;

3. referential phase 2 : images put into language in early draft form;

4. reformulation/insight: study of images, rewriting and reflection.

This last stage seems to parallel what is often the most fascinating part of the writing process: working out what you've written, and trying to find what the poem wants to say-what shape in language the images demand, how the poem can best be enabled to be itself, through the conscious manipulation of rhythm, sound, image, metaphor, and other literary techniques.

Bucci goes on to describe an experimental application of the theory of the referential cycle. She examined the writings of a number of students in a study by Pennebaker and Francis in 1994, which indicated that those asked to write about their thoughts and feelings about coming to college showed more positive effects than those asked to write about neutral subjects. Positive effects included higher grades and fewer visits to the university health centre. Writings were analysed to determine levels of emotional tone, abstraction and referential activity and these mapped onto the health improvements or otherwise experienced The results showed that the students who had become healthier began with high levels of concrete detail and emotional content in their writings, with little abstract language. As the writing progressed, levels evened out, indicating greater integration and assimilation. The group who actually become worse during the study started out with high levels of abstract language, lower levels of referential activity and emotion, and stayed at this level.

If we accept that creative writing will tend to have high levels of specificity and low levels of abstraction, Bucci's findings - combined with the results of my own study of the two groups of creative writerswould indicate there may be some relationship between the creative writing process and therapeutic benefits, in addition or complementary to that stemming from content disclosure. This would be backed up by some of the findings from the poets and mental health service users, who tended to emphasise the important role played by the craft and shaping elements of writing. Their common belief that choosing words, not just finding them, played a part in the impact on wellbeing is supported by Bucci's work, which implies that specificity can assist health. Virginia Woolf, with whom I began, said that writing helped her to "Observe my own despondency. By that means it becomes serviceable". ${ }^{28}$

This would seem to summarise the extent of my conclusions. That most writers felt there were benefits can be linked to this "becom[ing] serviceable", which does not mean that the problems necessarily were cured. This would thus not contradict research which indicates that writers are very likely to suffer from mental illhealth or depression. ${ }^{29}$ There is a need for further, much more detailed research into how the creative writing interacts with wellbeing, combining a literary approach with psychological and clinical evidence. This should examine, through detailed case studies, to what extent writing can assist mental health and how the literary-ness interacts with disclosure. Perhaps at a certain level of insight the benefit becomes a burden. Post suggests that the struggle to put vivid imagery into words can become associated with a kind of mental hyperactivity which ultimately leads to depression. Such future research should perhaps be informed by the irony of the following quotation from Virgina Woolf's diary: "And now with some pleasure I find that it's seven; and must cook dinner. Haddock and sausage meat. I think it is true that one gains a certain hold on sausage and haddock by writing them down". ${ }^{28}$

This was written on March 8th 1941, just days before Woolf committed suicide.

Mark Robinson is Head of Film, Media and Literature at the Northern Arts Board, Newcastle-upon-Tyne, working in partnership with the Centre for Arts and Humanities in Health Medicine, University of Durham.a.m.robinson@durham.ac.uk

\section{References and notes}

1 Leedy JJ, ed. Poetry therapy. Philadelphia: Lippincott, 1969.

2 Barr T. Writing on social issues within the community: "but do they write good poetry?" Paper given at Poetry and the Public Sphere conference, Rutgers University, New York, archived at http://english.rutgers.edu/barr.htm; 1997

3 Longo PJ. Poetry as therapy. Fournal of Poetry Therapy 1999;10: $12-16$

4 Bolton G The therapeutic potential of creative writing. London: Jessica Kingsley, 1999.

5 Jensen CM, Blair SEE. Rhyme and reason: the relationship between creative writing and mental wellbeing. British fournal of Occupational Therapy 1997;60:525-30.

6 of Occupational Therapy 1997;60:525-30.

6 Woolf V. A writer's diary. London: Hogarth Press, 1953: 96. Press, 1997:17.

8 Kress, 1997:17. ing poetry. New York: Scribner, 1998.

9 Richards MC. Centering in pottery, poetry and the person. Middletown, Conn: Wesleyan University Press, 1962:25.

10 Trilling L. Art and neurosis. In Anderson W, ed. Therapy and the arts: tools of consciousness. New York: Harper Colophon, 1977.

11 Eliot TS. Tradition and the individual talent. In: Selected prose. Harmondsworth: Penguin, 1953: 30

12 Ackroyd P. T S Eliot. Harmondsworth: Penguin, 1993.

3 Sexton A. The complete poems. Boston: Houghton Mifflin, 1981:

14 Winnicott DW. Playing and reality. Harmondsworth: Penguin, 1974.

15 Rimbaud A. Selected poems. Harmondsworth: Penguin, 1962: 10.

16 See reference 10:170.

16 See reference 10:170.

17 Winokur J. Writers on writing. London: Headline, 1989: 146. Feb 23: 5 .

19 Alvarez AA. The new poetry. Harmondsworth: Penguin, 1962: 25

20 Goldberg N. Wild mind. London: Rider, 1991: 69.

21 Smyth JM, Stone AA, Hurewitz A, Kael A. Effects of writing about stressful experiences on symptom reduction in patients with asthma or rheumatoid arthritis. Fournal of the American Medical Association 1999;281:1304-9.

22 See reference $4: 199$

23 See reference 4: 200 .

24 See reference $17: 147$

25 Bucci W. The power of the narrative: a multiple code account. In: Pennebaker JW, ed. Emotion, disclosure and health Washington, DC: American Psychological Association, 1995: 93-123.

26 See reference 25: 99 .

26 See reference 25: 99

28 See reference 20: 3 .

29 Post F. Verbal creativity, depression and alcoholism: an investigation of one hundred American and British writers. British fournal of Psychiatry 1996;168:545-55. 